\title{
KOTAK POP-UP BERBASIS PROBLEM SOLVING: PENGEMBANGAN MEDIA PEMBELAJARAN PADA MATERI CAHAYA DAN ALAT-ALAT OPTIK UNTUK KELAS VIII SMP
}

\author{
Septi Mahayani ${ }^{1}$, Irwandani ${ }^{2}$, Yuberti $^{3}$, Widayanti ${ }^{4}$ \\ 1,2,3,4Pendidikan Fisika, Universitas Islam Negeri Raden Intan Lampung \\ ${ }^{4}$ Pendidikan Fisika, Universitas Lampung \\ E-mail: irwandani@radenintan.ac.id
}

DOI: 10.26418/jpmipa.v9i2.25847

\begin{abstract}
This research aims to; 1) determine the feasibility of learning media in the form of a pop-up box based on problem solving as a media for learning physics, 2) to know the attractiveness of learning media in the form of pop-up box based on problem solving as a medium of physics learning. This research is an $R \& D$ research that adopts the development of Borg \& Gall yang has been modification by Sugiono. Subjects this are students class VIII Public Junior High School 5 Bandarlampung, WIYATAMA Junior High School Bandarlampung and MTS Al-Huda Jati Agung, questionnaire instrument is distributed to material experts, media experts, physics educators and learners. Questionnaire validation to test the quality of learning media and questionnaire response learners to determine the response of learners to learning media developed. The type of data generated is qualitative data which is analyzed by guidance criteria of rating category to determine product quality using Likert scale. The results of this study are; 1) produce a pop-up box product as a learning medium; the quality of products that have been developed "very feasible" with the percentage of material expert assessment $89.67 \%$ and media experts 89.77\%; 2) small group test responses at 3 (three) schools with an average percentage of $95.47 \%$ are considered very attractive and the average response in field trials of $93.60 \%$ is considered attractive. The learning media of problem solving pop-up box is very feasible and very interesting.

Keywords: Research and Development, Learning Media, Pop-Up Box.
\end{abstract}

Pendidikan dalam era ini menjadi salah satu hal yang sangat penting bagi kehidupan manusia (Cahye, 2018), karena pendidikan merupakan sarana untuk mencapai tujuan suatu bangsa dan sarana untuk mencetak sumber daya manusia yang berkualitas (Irwandani, Latifah,
Asyhari, Muzannur, \& Widayanti, 2017). Dua konsep pendidikan yang saling berkaitan adalah belajar (learning) dan mengajar (intruction). Dua hal ini terdapat dalam proses pembelajaran yang disesuaikan dengan tujuan pembelajaran. 
Tujuan pembelajaran adalah adanya perubahan perilaku dan tingkah laku yang positif dari peserta didik setelah mengikuti proses pembelajaran (Sunhaji, 2014). Di Indonesia tujuan pembelajaran dapat di capai melalui kurikulum (Mustaqim, 2014). Kurikulum yang mutakhir adalah kurikulum 2013 (Pratama, 2016; Rakhmawati, Muspiroh, \& Azmi, 2016). Meskipun, kurikulum 2013 sudah banyak diterapkan di berbagai sekolah, namun pada beberapa penelitian kurikulum 2013 belum sepenuhnya dapat diterapkan bahkan masih banyak yang menggunakan kurikulum lama (Mustaqim, 2014; Qomariyah, 2014; Rakhmawati et al., 2016), yang hakikatnya masih menggunakan metode ceramah (Sitaresmi, Saputro, \& Utomo, 2017). Paradigma baru dalam pembelajaran salah satunya pembelajaran IPA terutama fisika adalah pembelajaran di mana peserta didik tidak hanya mempelajari konsep-konsep dan prinsip-prinsip fisika secara verbalitas, pengenalan rumus-rumus dan pengenalan istilah-istilah melalui latihan verbal (Fauzan, Gani, \& Syukri, 2017), namun hendaknya pembelajaran sains lebih banyak memberikan pengalaman belajar melalui proses penemuan serta melatih peserta didik untuk dapat menerapkan pengetahuannya dalam kehidupannya sehari-hari (Suhendri \& Mardalena, 2012).

Salah satu usaha untuk memperbaiki kualitas pembelajaran dalam mata pelajaran fisika adalah dengan mengembangkan media pembelajaran yang inovatif (Matsun, Ramadhani, \& Lestari, 2018) dan menggunakan model pembelajaran yang bervariasi (Erlinda, 2017; Irwandani \& Rofiah, 2015) seperti model Problem Solving yang merupakan salah satu modifikasi dari teknik bertanya yang menitik beratkan pada kemampuan merumuskan pertanyaan atau masalah. Secara umum model Problem Solving mencakup lima langkah antara lain: (1) Identifikasi masalah; (2) Penggambaran masalah; (3) Pemilihan strategi pemecahan masalah; (4) Implementasi strategi pemecahan masalah; dan (5) Evaluasi hasil (Patnani, 2013).

Penggunaan media pembelajaran yang tepat mampu menarik perhatian siswa serta memudahkan siswa dalam memahami materi (Sohibun \& Ade, 2017). Berdasarkan alasan tersebut, diperlukan sebuah inovasi dalam pembelajaran fisika terutama dalam penggunaan media pembelajaran sebagai sarana belajar. Media pembelajaran yang perlu dikembangkan adalah media pembelajaran yang memungkinkan peserta didik menemukan sendiri konsep masalah yang ditemukan pada saat proses pembelajaran. Untuk menunjang penggunaan media pembelajaran yang dimaksud perlu diadakan pengembangan media pembelajaran.

$$
\text { Mengingat luasnya }
$$
permasalahan yang ditemukan oleh peserta didik dalam peroses pembelajaran fisika, salah satunya materi yang sering dialami peserta didik yaitu materi cahaya dan alat-alat optik, maka penelitian ini difokuskan pada materi cahaya dan alat-alat optik. Akhmad Sudrajat dalam makalah mengemukakan bahwa media 
pembelajaran adalah teknologi pembawa pesan yang dapat dimanfaatkan untuk keperluan pembelajaran. Sementara itu, Briggs berpendapat bahwa media pembelajaran adalah sarana fisik untuk menyampaikan isi/materi pembelajaran seperti: buku, film, video dan sebagainya. (Umar, 2014). Adapun manfaat media dalam pembelajaran adalah sebagai berikut : 1) meningkatkan mutu pendidikan dengan cara meningkatkan kecepatan belajar (rato of learning), 2) memberi kemungkinan pendidikan yang sifatnya lebih individual, 3) memberi dasar pengajaran yang lebih ilmiah. (Mahnun, 2012).

Berdasarkan hasil observasi dengan pendidik maupun dengan peserta didik di beberapa sekolah yaitu di SMPN 5 Bandarlampung, SMP WIYATAMA Bandarlampung dan MTS Al-Huda Jati Agung diketahui masalah yang sering dihadapi peserta didik di kelas salah satunya adalah kurangnya memahami hal-hal penting dari materi yang disajikan pendidik. Selain itu kurangnya inovasi dan kreatifitas tenaga pendidik untuk mengembangkan media pembelajaran. Hal ini terlihat dari hasil analisis kebutuhan yang telah dilakukan dengan menggunakan angket yang telah dibagikan kepada peserta didik dan pendidik. Dari hasil analisis kebutuhan tersebut juga didapatkan hasil bahwa pendidik perlu menggunakan media pembelajaran. Oleh karena itu dibutuhkan suatu perangkat pembelajaran untuk mempermudah menyampaikan materi fisika yang dapat membantu memahami konsep yang abstrak dan menghubungkannya dengan kehidupan sehari-hari yaitu dengan menggunakan media pembelajaran yang menarik.

Pelaksanaan pembelajaran fisika yang aktif dan kreatif dapat diwujudkan dengan pengembangan media pembelajaran fisika dengan menggunakan media pembelajaran berupa kotak pop-up (Cahyani, Wiranti, \& Hasanah, 2014; Safitri \& Norma, 2014; Safri, Sari, \& Marlina, 2017). Beda penelitian dengan sebelumnya pada penelitian ini menggunakan kotak pop-up dan materi yang digunakan adalah fisika. Berbagai pemaparan di atas peneliti melakukan penelitian Media Pembelajaran Kotak Pop-Up Berbasis Problem Solving untuk Pembelajaran Fisika Materi Cahaya dan Alat-alat Optik.

\section{METODE PENELITIAN}

Prosedur penelitian pengembangan berpedoman dari desain penelitian pengembangan media instruksional oleh Borg and Gall yang dimodifikasi Sugiyono meliputi (Sugiono: 297): 


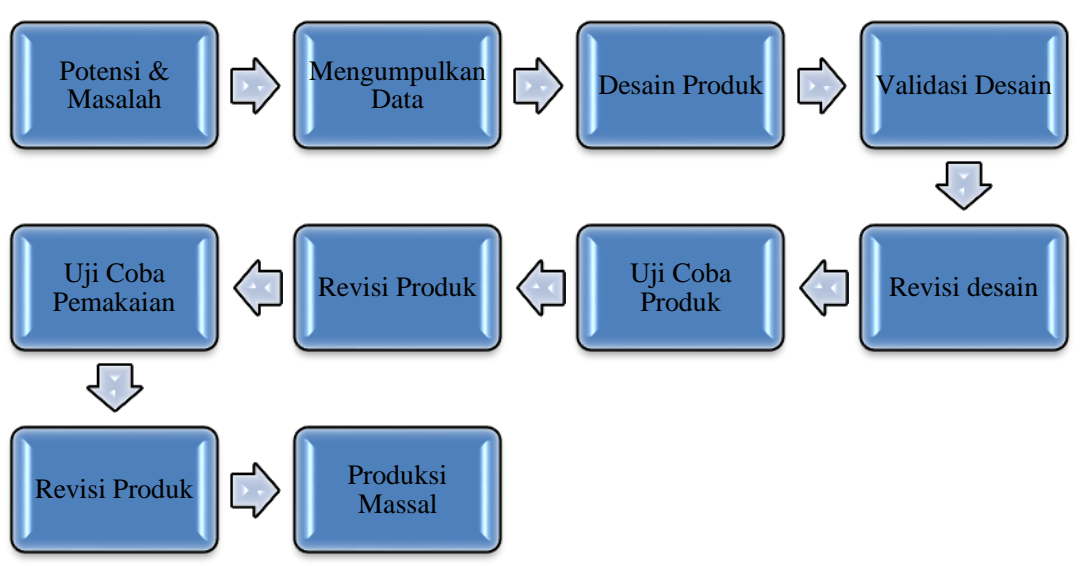

Gambar 1. Desain penelitian dan pengembangan.

Pada penelitian ini desain penelitian dibatasi tujuh langkah karena ketujuh langkah tersebut sudah menjawab tujuan penelitian. Subjek penelitian adalah peserta didik kelas VIII di SMPN 5 Bandarlampung, SMP WIYATAMA Bandarlampung dan MTS Al-Huda Jati Agung. Data penelitian dikumpulkan dengan menggunakan angket, analisa data yang digunakan skala likert (Tabel 1) (Riduwan, 2005).

Tabel 1. Aturan pemberian skor.

\begin{tabular}{c|c}
\hline Kategori & Skor \\
\hline SB (Sangat Baik) & 5 \\
\hline B (Baik) & 4 \\
\hline C (Cukup) & 3 \\
\hline K (Kurang) & 2 \\
\hline SK (Sangat Kurang) & 1 \\
\hline
\end{tabular}

Cara menentukan interpretasi data sebagai berikut (Nurmayanti, Rosilawati, \& Fadiawati, 2017):

$$
\bar{S}=\frac{\sum S}{n}
$$

Keterangan:

$\bar{S} \quad=$ Nilai rata-rata setiap

pernyataan

$\sum S \quad=$ Jumlah total skor

$\mathrm{n} \quad=$ Banyak responden
Intrepretasi skor yang diperoleh dengan ketentuan pada Tabel 2 berikut (Riduwan, 2010):

Tabel 2. Interpretasi kelayakan dan kemenarikan media pembelajaran.

\begin{tabular}{cc}
\hline $\begin{array}{c}\text { Skor kelayakan } \\
\text { media } \\
\text { pembelajaran }\end{array}$ & Kriteria \\
\hline $80>\mathrm{S} \leq 100 \%$ & $\begin{array}{c}\text { Sangat layak/ } \\
\text { sangat menarik }\end{array}$ \\
\hline $60>\mathrm{S} \leq 80 \%$ & Layak/menarik \\
\hline $40>\mathrm{S} \leq 60 \%$ & $\begin{array}{c}\text { Cukup layak/ } \\
\text { cukup menarik }\end{array}$ \\
\hline $20>\mathrm{S} \leq 40 \%$ & $\begin{array}{c}\text { Kurang layak/ } \\
\text { kurang menarik }\end{array}$ \\
\hline $\mathrm{S} \leq 20 \%$ & $\begin{array}{c}\text { Sangat layak/ } \\
\text { sangat layak }\end{array}$ \\
\hline
\end{tabular}

HASIL DAN PEMBAHASAN

Berdasarkan Tafsir Al-Qur'an Hidayatul Insan menyatakan penggunaan media dalam pembelajaran harus mempertimbangkan aspek pesan yang disampaikan adalah positif dan bahasa yang santun sebagai sarana penyampaian pesan, dan jika ditolak pun seorang pendidik harus menjelaskannya dengan bahasa yang logis, agar peserta didik dapat 
menerima dengan baik. (Ramli, 2015). Proses belajar mengajar pada dasarnya juga merupakan proses komunikasi, sehingga media yang digunakan dalam pembelajaran disebut media pembelajaran.

Media pembelajaran merupakan salah satu media pembelajaran yang dapat digunakan pendidik dalam melaksanakan kegiatan pembelajaran dan peserta didik dapat lebih mudah memahami konsep pembelajaran dengan baik. Media pembelajaran merupakan bagian dari sumber belajar yang merupakan kombinasi antara perangkat lunak (bahan belajar) dan perangkat keras (alat belajar). (Muhson, 2010). Pembelajaran dengan menggunakan media pembelajaran tidak hanya sekedar menggunakan kata-kata (simbol verbal) (Asyhari \& Silvia, 2016). Pemanfaatan media pengajaran pada hakekatnya bertujuan untuk meningkatkan efisiensi dan efektivitas pengajaran. Dengan bantuan media, siswa diharapkan menggunakan sebanyak mungkin alat inderanya untuk mengamati, mendengar, merasakan, menghayati dan pada akhirnya memiliki sejumlah pengetahuan, sikap dan keterampilan sebagai hasil belajar. (Umar, 2014).

Hal pertama yang harus diperhatikan dalam proses pembelajaran dan berinteraksi dengan peserta didik adalah cara menarik perhatian. Ketika peserta didik telah merasa tertarik dengan pembelajaran, maka akan lebih mudah bagi peserta didik untuk menerima dan memahami pelajaran. Salah satunya dengan menggunakan media kotak Pop-Up. Kotak pop-up dengan kalimat yang tersembunyi, kertas yang ditarik, roda yang diputar, dan semua gambar yang dibuat 3 dimensi adalah cara yang mungkin sekali untuk menangkap perhatian peserta didik dengan cepat (Mariani \& Kusumawardani, 2014). Kotak Pop-up merupakan kotak yang ketika dibuka tutupnya halaman dapat bergerak dan muncul bentuk 3D. Popup mudah dibuka dan isinya berubahubah, sehingga setiap saat dapat membuat pembaca terpukau. (Cahyani, Wiranti, \& Hasanah, 2014). Pemilihan media kotak Pop- up sesuai dengan potensi visual peserta didik, juga dipandang praktis karena mudah dimainkan dan menarik. (K, 2015). Media kotak Pop-up memiliki beberapa kelebihan, diantaranya adalah sifatnya konkrit lebih realistis menunjukan pokok masalah dibandingkan dengan media verbal semata. Selain itu, media gambar dapat memperjelas masalah, dalam bidang apa saja dan untuk tingkat usia berapa saja. (Safitri \& Norma, 2014). Berikut hasil pengembangan media kotak Pop-Up fisika berbasis problem solving.

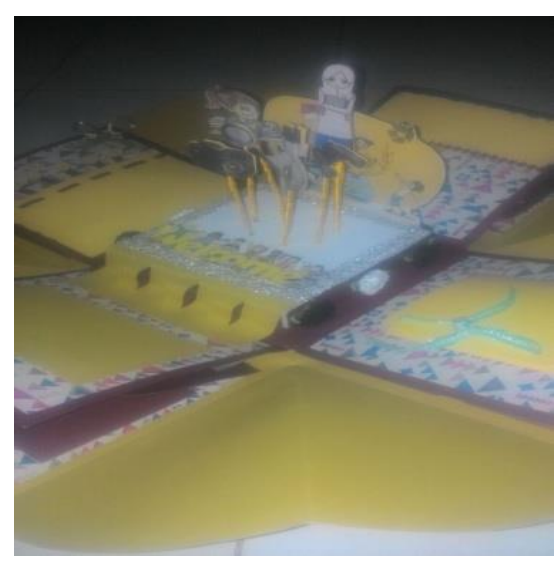

Gambar 2. Halaman kotak Pop-Up fisika. 


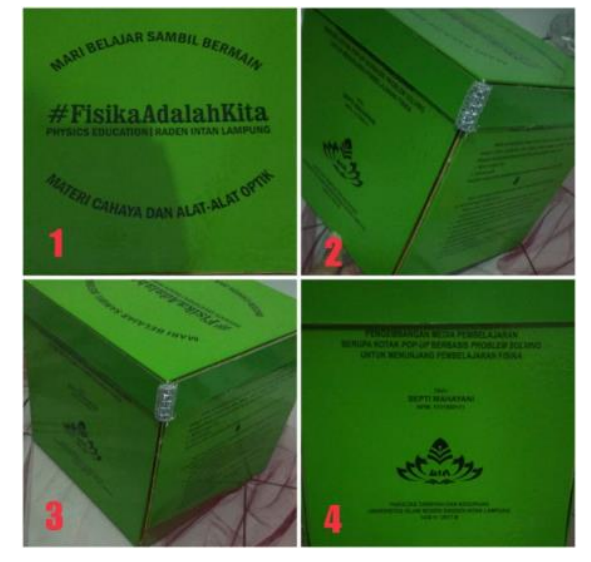

Gambar 3. Pengemasan kotak Pop$U p$ fisika.

Tahapan dalam pengembangan media Pop-Up fisika berbasis problem solving meliputi: tahapan awal melakukan observasi kesekolahsekolah. Hasil dari observasi yang dilakukan diketahui bahwa penggunaan media pembelajaran dalam pembelajaran belum maksimal dan media pembelajaran dibutuhkan dalam pembelajaran. Kemudian mengumpulkan alat dan bahan. Selanjutnya alat dan bahan dirangkai menjadi sebuah produk media pembelajaran fisika berupa kotak pop-up.

Produk yang telah dikembangkan kemudian divalidasi oleh beberapa ahli. Validasi dilakukan oleh 3 ahli materi dan 3 orang ahli media yang ahli dibidangnya.

1. Hasil validasi oleh ahli materi

Hasil validasi ahli materi mencakup 3 aspek penilaian yaitu: penyajian materi, keberadaan konsep dan penekanan materi. Hasil penilaian dari tiga ahli materi mendapatkan skor rata-rata sebesar 4,89 dengan kriteria kelayakan sebesar $89,69 \%$ dengan kategori "sangat layak", hal ini berarti media pembelajaran yang dikembangkan sudah sesuai dengan materi pembelajaran fisika dan layak digunakan dalam pembelajaran.

2. Hasil validasi ahli media tahap I Pada validasi yang dilakukan oleh ahli media yang dikembangkan sudah layak tetapi ada beberapa komponen yang harus diperbaiki pada aspek penyajian materi. Setelah melakukan perbaikan hasil penilaian yang mencakup 4 aspek penilaian yaitu: kemenarikan media pembelajaran, kriteria tampilan media, penyajian materi, dan keterlibatan peserta didik penilaian pada tahap I ini mendapatkan persentase kelayakan $83,55 \%$ dengan rata-rata skor 62,3 dengan katagori "layak".

3. Hasil validasi ahli media tahap II

Setelah produk direvisi sesuai dengan saran dan masukan validator diantaranya penambahan materi, penambahan gambar tiga dimensi, dan pemberian hiasan pada lembar materi, maka media pembelajaran yang dikembangkan sudah sangat layak digunakan. Hasil validasi tahap II mendapatkan persentase kelayakan sebesar $89,77 \%$ dengan katagori "sangat layak". Peningkatan validasi media terjadi karena peneliti telah memperbaiki sesuai dengan saran dan komentar ahli media.

4. Uji Coba Produk

Uji coba media kotak Pop-Up berbasis problem solving meliputi uji coba kelompok kecil dan uji coba lapangan. Uji coba ini diawali dengan mendemonstrasikan media pembelajaran tersebut kemudian 
mendiskusikan kaitannya dengan pokok bahasan cahaya dan alat-alat optik selanjutnya peserta didik diminta untuk mengisi angket respon terhadap media kotak PopUp berbasis problem solving. Uji coba kelompok kecil dilakukan pada 30 peserta didik yang terdiri dari 3 (tiga) sekolah SMPN 5
Bandarlampung, WIYATAMA Bandarlampung, dan MTS Al-Huda Jati Agung, dengan persentase rata-rata 95,47\% dengan katagori "Sangat Menarik". Data hasil uji coba kelompok kecil dapat dilihat pada grafik

berikut:

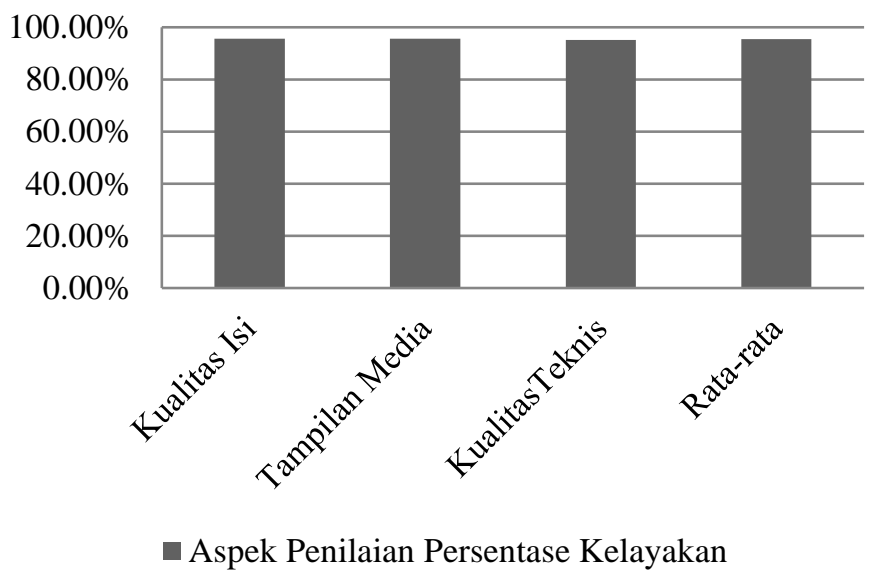

Gambar 4. Grafik presentase uji coba kelompok kecil.

Dari Gambar 4 grafik menunjukkan persentase penilaian uji coba kelompok kecil di tiga sekolah yaitu: SMPN 5 Bandarlampung, SMP WIYATAMA Bandarlampung, dan MTS Al-Huda Jati Agung, penilaian aspek kualitas isi mendapat persentase 95,68\% dengan kategori "sangat menarik". Penilaian aspek tampilan media mendapatkan persentase kelayakan 95,58\% dengan kategori "sangat menarik". Penilaian aspek kualitas teknis mendapat persentase kelayakan sebesar 95,15\% dengan kategori "sangat menarik". Hasil rata-rata uji coba kelompok kecil 95,47 dengan kategori sangat menarik. Data dari hasil uji coba lapangan dapat dilihat pada Gambar
5. Pada Gambar 5 penilaian produk yang meliputi 4 aspek memperoleh persentase rata-rata masing-masing sekolah yaitu: SMPN 5 Bandarlampung 92,54\%, SMP WIYATAMA Bandarlampung 95,50\%, dan MTS Al-Huda Jati Agung $92,87 \%$ dan rata-rata skor $93,60 \%$ ketiga persentase masingmasing sekolah dan persentase ratarata memiliki kategori sangat menarik. Hasil produk yang dikembangkan berupa kotak pop-up berbasis problem solving sebagai media pembalajaran fisika pada materi cahaya dan alat-alat optik. Media pembelajaran ini digunakan untuk menjelaskan materi-materi tentang cahaya dan alat-alat optik. 



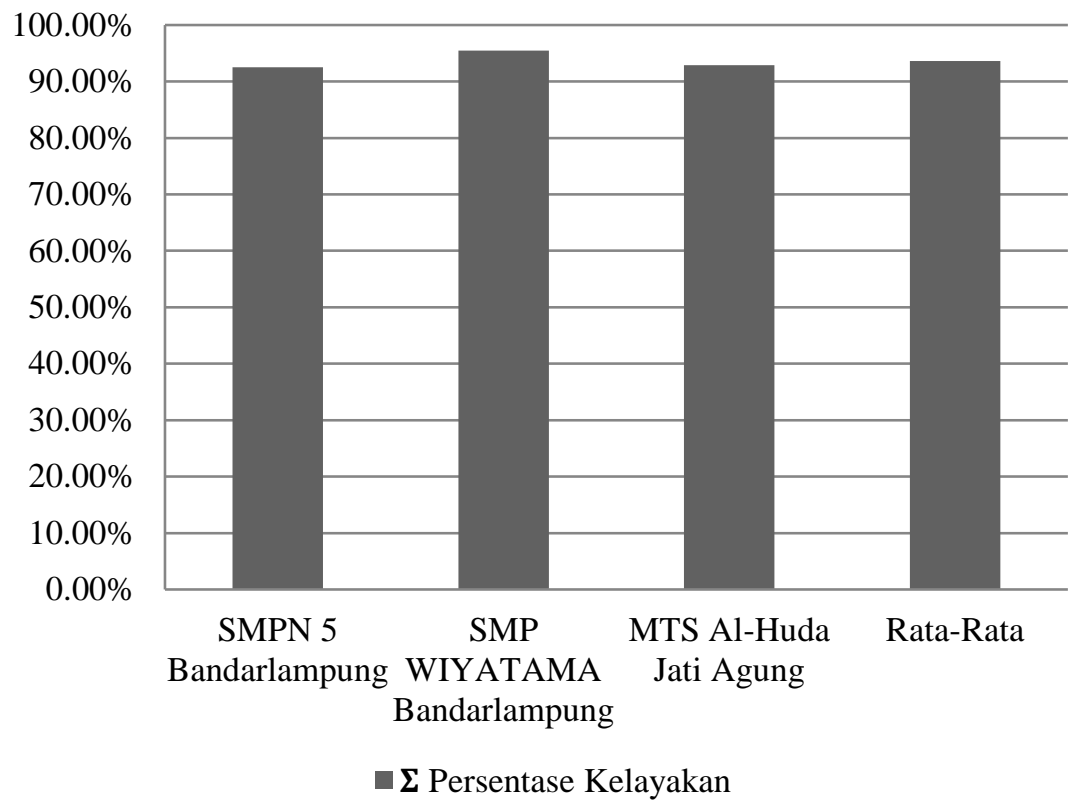

Gambar 5. Grafik persentase uji coba lapangan.

\section{SIMPULAN DAN SARAN}

Pengembangan

media

pembelajaran berupa Kotak Pop-Up

Berbasis Problem Solving

memperoleh persentase masing-

masing hasil penelitian yaitu hasil validasi media pembelajaran memperoleh persentase $89,77 \%$, validasi materi fisika $89,69 \%$ kedua validasi dengan kategori sangat layak. Persentase hasil uji coba yaitu : Hasil rata-rata uji coba kelompok kecil 95,47 dengan kategori sangat menarik dan hasil uji coba lapangan 93,60\% dengan kategori sangat menarik. Media pembelajaran Kotak Pop-Up berbasis problem solving dinyatakan sangat layak dan sangat menarik untuk menjadi sumber pembelajaran fisika. Kotak Pop-Up fisika dapat menjadi salah satu sumber pembelajaran fisika untuk memahami konsep cahaya dan alat-alat optik.
1. Bagi Sekolah, Sebaiknya media pembelajaran berupa Kotak Pop-Up ini digunakan pada pembelajaran fisika dan dapat diperbanyak guna menambah kreatifitas.

2. Bagi Tenaga Pendidik, kotak Pop-Up dapat digunakan sebagai penunjang pembelajaran dan sebaiknya memiliki minimal salah satu media pembelajaran untuk mempermudah proses belajar pengajar.

3. Bagi peneliti lain dapat mengembangkan media pembelajaran Kotak Pop-Up versi terbaru yang lebih unik dan menarik, dan Sebaiknya untuk mengembangkan pada materi fisika yang belum diintegrasikan dengan nilai-nilai keislaman. 
DAFTAR PUSTAKA

Asyhari, A., \& Silvia, H. (2016). Pengembangan Media Pembelajaran Berupa Buletin dalam Bentuk Buku Saku untuk Pembelajran IPA Terpadu. Jurnal Ilmiah Pendidikan Fisika Al-Biruni, 5(1), 1.

Cahyani, A. N., Wiranti, \& Hasanah, D. (2014). Pengembangan Modul Berbasis Pop Up Book pada Materi Alat-Alat Optik untuk Siswa SMPLB-B (Tunarungu) Kelas VIII. In Prosiding Seminar Nasional Pendidikan Fisika. Surakarta.

Cahye. (2018). Memotivasi Belajar Siswa Melalui Model Pembelajaran Cooperative Tipe Script pada Materi SPLDV di Kelas VIII Semester I SMP Negeri 3 Kubu. Jurnal Pendidikan Matematika dan IPA, 9(1), 1-14.

Erlinda, N. (2017). Peningkatan Aktivitas dan Hasil Belajar Siswa melalui Model Kooperatif Tipe Team Game Tournament pada Mata Pelajaran Fisika di SMK. Tadris: Jurnal Keguruan Dan Ilmu Tarbiyah, 2(1), 47-52. https://doi.org/10.24042/tadris.v $2 \mathrm{i} 1.1738$

Fauzan, M., Gani, A., \& Syukri, M. (2017). Penerapan Model Problem Based Learning Pada Pembelajaran Materi Sistem Tata Surya untuk Meningkatkan Hasil Belajar Siswa. Jurnal Pendidikan Sains Indonesia, 5(1), 27-35.
Irwandani, I., \& Rofiah, S. (2015). Pengaruh Model Pembelajaran Generatif Terhadap Pemahaman Konsep Fisika Pokok Bahasan Bunyi Peserta Didik MTs AlHikmah Bandar Lampung. Jurnal Ilmiah Pendidikan Fisika Al-Biruni, 4(2), 165-177.

Irwandani, Latifah, S., Asyhari, A., Muzannur, \& Widayanti. (2017). Modul Digital Interaktif Berbasis Articulate Studio'13: Pengembangan pada Materi Gerak Melingkar Kelas X. Jurnal Ilmiah Pendidikan Fisika Al-Biruni, 6(2), 221-231. https://doi.org/10.24042/jipfalbi runi.v6i2.1862

K, O. A. (2015). Pengembangan Popup Book Materi Kalor untuk Meningkatkan Motivasi dan Prestasi Belajar Peserta Didik Kelas VIII. Wiyatmo, Yusman, 4(3).

Mahnun, N. (2012). Media Pembelajaran (Kajian terhadap Langkah-langkah Pemilihan Media dan Implementasinya dalam Pembelajaran). Jurnal Pemikiran Islam, 37(1), 27-35.

Mariani, S. W., \& Kusumawardani, E. (2014). The effectiveness of Learning by PBL Assisted Mathematics Pop Up Book Againts The Spatial Ability in Grade VIII on Geometry Subject Matter. International Journal of Education and Research, 2(2), 531-548. 
Matsun, Ramadhani, D., \& Lestari, I. (2018). Pengembangan Bahan Ajar Listrik Magnet Berbasis Android di Program Studi Pendidikan Fisika IKIP PGRI Pontianak. Jurnal Pendidikan Matematika dan IPA, 9(1), 99107.

Muhson, A. (2010). Pengembangan Media Pembelajaran Berbasis Teknologi Informasi. Jurnal Pendidikan Akuntansi Indonesia, 8(2), 1-10.

Mustaqim, R. A. (2014). Kesiapan Sekolah Dalam Mengimplementasikan Kurikulum 2013 Pada Mata Pelajaran Ekonomi. Jurnal Pendidikan Ekonomi IKIP Veteran Semarang, 2(1), 12-20.

Nurmayanti, Rosilawati, I., \& Fadiawati, N. (2017). Pengembangan E-Book Interaktif Berbasis Representasi Kimia pada Materi Ikatan Kimia. Jurnal Pendidikan Dan Pembelajaran Kimia, 6(1), 160-172.

Patnani, M. (2013). Upaya Meningkatkan Kemampuan Problem Solving pada Mahasiswa. Jurnal Psikogenesis, 1(2), 130-142.

Pratama, R. A. (2016). Pengembangan Modul Membaca Kritis Dengan Model Instruksi Langsung Berbasis Nilai Karakter. DIALEKTIKA: Jurnal Bahasa, Sastra, Dan Pendidikan Bahasa Dan Sastra Indonesia, 3(2), 173-190.
Qomariyah. (2014). Kesiapan Guru dalam Menghadapi Implementasi Kurikulum 2013. Jurnal Pendidikan Ekonomi IKIP Veteran Semarang, 2(1), 21-35.

Rakhmawati, S., Muspiroh, N., \& Azmi, N. (2016). Analisis Pelaksanaan Kurikulum 2013 Ditinjau dari Standar Proses dalam Pembelajaran Biologi Kelas X di Sma Negeri 1 Krangkeng. Scientiae Educatia: Jurnal Sains Dan Pendidikan Sains, 5(2), 156-164. Retrieved from

www.syekhnurjati.ac.di/jurnal/i ndex.php/sceducatia

Ramli, M. (2015). Media Pembelajaran Dalam Perspektif Al-Qur'an DanAl-Hadits. Jurnal Kopertais Wilayah XI Kalimantan, 13(23).

Riduwan. (2005). Skala Pengukuran Variabel-variabel Penelitian. Bandung: Alfabeta.

Riduwan. (2010). Skala Pengukuran variable-variabel penelitian. Bandung: Alfabeta.

Safitri, N., \& Norma. (2014). Pengembangan Media Pop-up Book untuk Keterampilan Menulis Narasi Tunarungu Kelas IV. Jurnal Pendidikan Khusus, 4(1).

Safri, M., Sari, S. A., \& Marlina. (2017). Pengembangan Media Belajar POP-UP Book pada Materi Minyak Bumi. Jurnal Pendidikan Sains Indonesia, 5(1), 107-113. 
108 Jurnal Pendidikan Matematika dan IPA Vol. 9 No. 2 Juli 2018: 98-108

Sitaresmi, K. S., Saputro, S., \& Utomo, S. B. (2017). Penerapan Pembelajaran Project Based Learning (PjBL) untuk Meningkatkan Aktivitas dan Prestasi Belajar Siswa pada Materi Sistem Periodik Unsur (SPU) Kelas X MIA 1 SMA Negeri 1 Teras Boyolali Tahun Pelajaran 2015/2016. Jurnal Pendidikan Kimia, 6(1), 54-61. Retrieved from http://jurnal.fkip.uns.ac.id/index .php/kimia/article/view/9405

Sohibun, \& Ade, F. Y. (2017). Pengembangan Media Pembelajaran Berbasis Virtual Class Berbantuan Google Drive. Pengembangan Media
Pembelajaran Berbasis Virtual Class Berbantuan Google Drive, 2(2), 121-129.

Suhendri, H., \& Mardalena, T. (2012). Pengaruh Metode Pembelajaran Problem Solving terhadap Hasil Belajar Matematika Ditinjau dari Kemandirian Belajar. Jurnal Formatif, 3(2), 105-114.

Sunhaji. (2014). Konsep Manajemen Kelas dan Implikasinya dalam Pembelajaran.

Jurnal Kependidikan, 2(2), 30-46.

Umar. (2014). Media Pendidikan: Peran dan Fungsinya dalam Pembelajaran. Jurnal Tarbawiyah, 11(1), 131-144. 